\title{
Modeling \& transient analysis of DFIG based wind farm
}

\author{
S. Nagendra Kumar ${ }^{1}$, T. Suman Poul Reddy ${ }^{1}$, A. Nagaraju ${ }^{2}$, V. Narsi Reddy ${ }^{3}$, K. Veerendranath ${ }^{4}$, S. Hareesh $^{5}$, \\ S. Chaithanya ${ }^{4}$, S. Krishnarjuna Rao ${ }^{4}$ \\ ${ }^{1}$ Dept. of EEE, Universal College of Engg \& Tech, Guntur, A.P, India \\ ${ }^{2}$ Dept. of EEE, GITAM University, Bangalore, India \\ ${ }^{3}$ Dept. of EEE, Malineni Perumallu Educational Society's Group of Institutions, Guntur, A.P, India \\ ${ }^{4}$ Dept. of EEE, Rajeev Gandhi Memorial College of Engg \& Tech, Nandyal, A.P, India \\ ${ }^{5}$ Dept. of EEE, Sree Vidyaniketan Engineering College, Tirupathi, A.P, India \\ *Corresponding author E-mail: seethachaithu@gmail.com
}

\begin{abstract}
This manuscript presents the modeling and simulation studies of grid connected Doubly Fed Induction Generator (DFIG) based wind farm. In current scenario, DFIG is used for the large scale wind energy systems. DFIG is high sensitive for the faults on the system due to termi-nals of stator directly fed to the grid. In this work the dynamic response of the proposed system under varying wind speeds and three transi-ent faults at different locations for different durations are studied.
\end{abstract}

Keywords: DFIG; LVRT; Grid; Fault.

\section{Introduction}

In the past decade, the penetration of renewable energy such as solar, wind etc., are increasing worldwide. Especially renewable wind generators are gaining much more attention because of its order of megawatts. In future, in India wind turbine installations are going to increase. India's largest successful renewable energy installation is wind energy sector. In 1983-84, in India the wind installations were initiated. Currently, India's wind power installation capacity is more than 26,000 MW. Fig.1. shows the cumulative wind power installation capacity of India as compared to different nations [1].

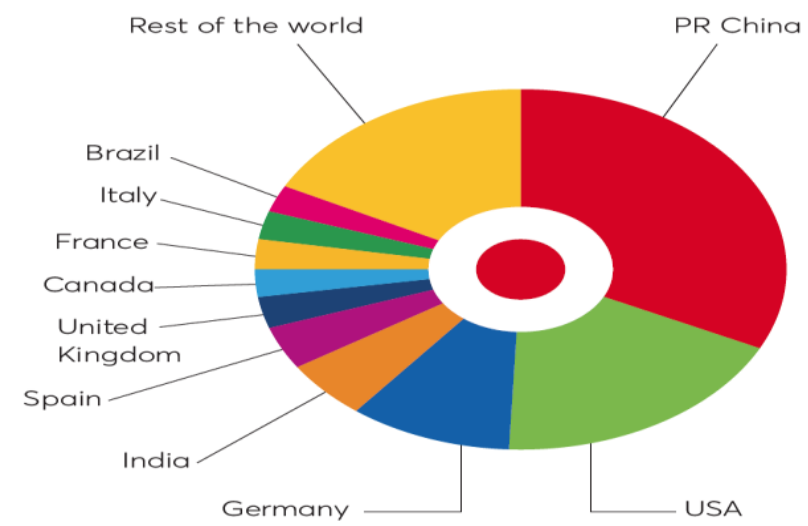

Fig. 1: The Cumulative Wind Power Installation Capacity of India As Compared to Different Nations.

The conventional generator models which are used for the wind energy generation are Squirrel Cage Induction Generator (SCIG) wind turbines and Permanent Magnet Synchronous Generator (PMSG) wind turbines. Presently, DFIG based wind turbines are advantageous than the conventional models due to its higher effi- ciency and low converter rating. It has capability of independent control of both active and reactive power but it is much sensitive for the grid faults because terminals of stator directly fed to the grid $[2,3]$. Grid integration of wind energy needs to follow the grid codes. As per the American Wind Energy Association (AWEA), the grid codes which are include Low Voltage Ride Through (LVRT), Fault Ride Through (FRT) capacity and reactive power capabilities [4-6].

In this manuscript transient response of the grid connected DFIG based wind farm is analyzed. Section II presents the modeling of wind turbine. The mathematic modeling of DFIG was carried out in Section III. Section IV explains simulation results of the proposed configuration by using Matlab/Simulink. Finally, section V presents the conclusion of this paper.

\section{Wind turbine}

The steady state power characteristic expression for output of wind turbine is given by

$$
P_{m}=\frac{1}{2} \rho A V_{w}^{2} C_{p}(\lambda, \beta)
$$

Where $P_{m}$ is the mechanical power, $\rho$ is air density $\left(\mathrm{Kg} / \mathrm{m}^{3}\right), V_{w}$ is wind speed $(\mathrm{m} / \mathrm{s}), \mathrm{C}_{\mathrm{p}}$ is the performance co-efficient and is given by [7]

$$
C_{p}(\lambda, \beta)=C_{1}\left(\frac{C_{2}}{\lambda_{i}}-C_{3} \beta-C_{4}\right) e^{\frac{-C_{5}}{\lambda_{i}}}+C_{6} \lambda
$$

Where

$\mathrm{C}_{1}=0.5176, \mathrm{C}_{2}=116, \mathrm{C}_{3}=0.4, \mathrm{C}_{4}=5, \mathrm{C}_{5}=21, \mathrm{C}_{6}=0.0068$. 


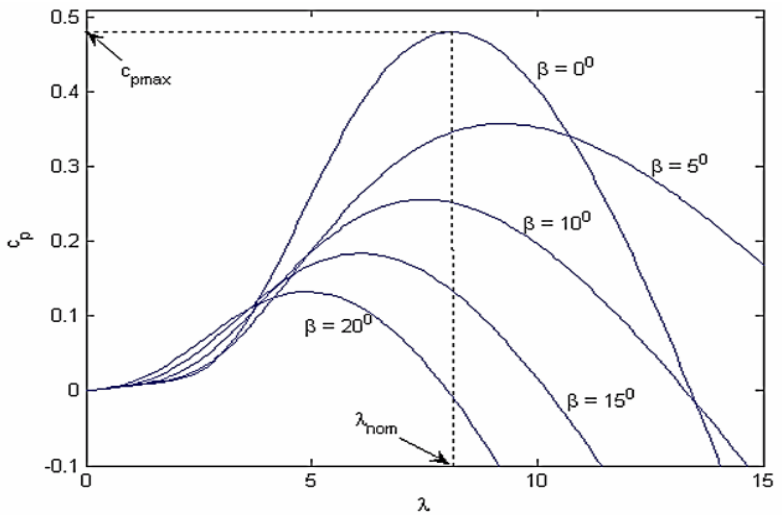

Fig. 2: $\mathrm{CP}-\Lambda$ Characteristics of the Wind Turbine.

The $\mathrm{Cp}-\lambda$ characteristics are shown in Fig. 2. From graph it can be observed that at $\lambda=8.1$, the maximum value of efficiency is attained by the wind turbine. Fig. 3 shows the wind turbine output power characteristics. From the graph it can be observed that the maximum power can be achieved when turbine speed at 1.2pu and when at pitch angle zero.

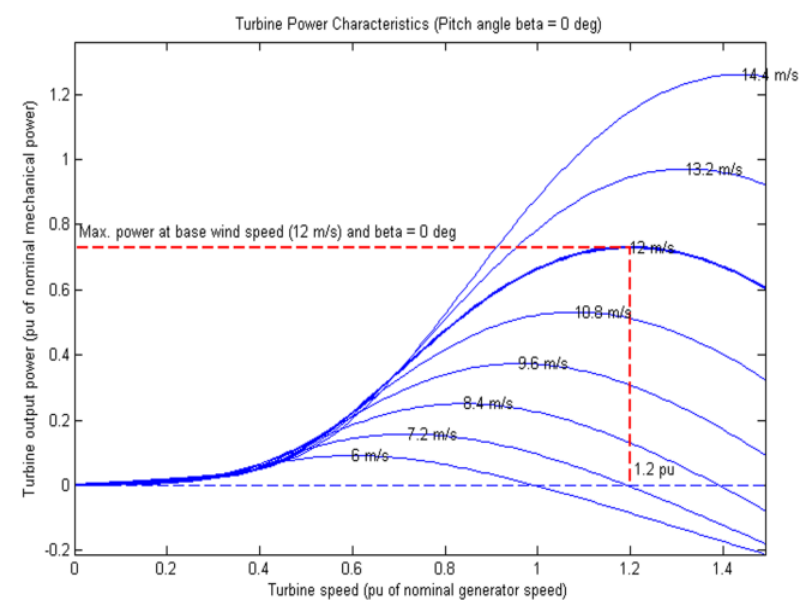

Fig. 3: Output Power Characteristics of Wind Turbine.

\section{Modeling of DFIG}

DFIG is a wound rotor machine with AC-DC-AC four quadrant converters is shown in Fig. 4. The constant DC Link voltage is maintained by the grid side converter of the DFIG. The machine side converter maintains the power factor by controlling the torque and speed of the machine [8-9].

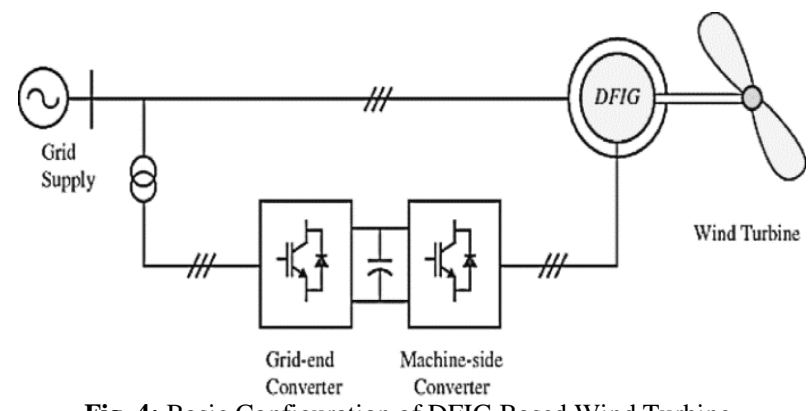

Fig. 4: Basic Configuration of DFIG Based Wind Turbine.

\subsection{Dynamic model of DFIG}

The stator and rotor windings electrical equations are in park's reference model expressed by [10-11]

$V_{d s}=R_{s} I_{d s}+\frac{d \phi_{d s}}{d t}-\omega_{s} \phi_{q s}$

$$
\begin{aligned}
& V_{q s}=R_{s} I_{q s}+\frac{d \phi_{q s}}{d t}+\omega_{s} \phi_{d s} \\
& V_{d r}=R_{r} I_{d r}+\frac{d \phi_{d r}}{d t}+\left(\omega_{s}-\omega_{r e}\right) \phi_{q r} \\
& V_{q r}=R_{r} I_{q r}+\frac{d \phi_{q r}}{d t}+\left(\omega_{s}-\omega_{r e}\right) \phi_{d r}
\end{aligned}
$$

Where Rs \& $\mathrm{Rr}$ are the phase resistances of stator and rotor, $\omega \mathrm{s}$ is stator electrical speed and the stator and rotor fluxes are expressed as

$$
\begin{aligned}
& \phi_{d s}=\left(L_{l r}+L_{m}\right) I_{d s}+L_{m} I_{d r} \\
& \phi_{q s}=\left(L_{l s}+L_{m}\right) I_{q s}+L_{m} I_{q r} \\
& \phi_{d r}=\left(L_{l r}+L_{m}\right) I_{d r}+L_{m} I_{d s} \\
& \phi_{q r}=\left(L_{l r}+L_{m}\right) I_{q r}+L_{m} I_{q s}
\end{aligned}
$$

Where Lls, Lir and Lm are the leakage and mutual inductances of stator and rotor respectively. The stator and rotor active and reactive power can be represented as:

$$
\begin{aligned}
& P_{s}=V_{d s} I_{d s}+V_{q s} I_{q s} \\
& Q_{s}=V_{q s} I_{d g}-V_{d s} I_{q g} \\
& P_{r}=V_{d r} I_{d r}+V_{q r} I_{q r} \\
& Q_{r}=V_{q r} I_{d r}-V_{d r} I_{q r}
\end{aligned}
$$

\subsection{DFIG based wind farm}

The DFIG based wind farm for transient analysis is shown in Fig. 5. The wind farm consists of three DFIGs. All the DFIG machines are having $1.5 \mathrm{MW}$ rating and connected to the grid by $25 \mathrm{KV} / 575 \mathrm{~V}$ three phase transformers. For the transient analysis three fault points has been considered at different locations of the system named F1, F2 \& F3 as represented in Fig. 5. The DFIG based wind turbine parameters represented in Table.1.

Table 1: DFIG Based Wind Turbine Parameters

\begin{tabular}{ll}
\hline Rated Power & $1.5 \mathrm{MVA}$ \\
\hline L-L Voltage & $1000 \mathrm{~V}$ \\
Frequency of operation & $60 \mathrm{~Hz}$ \\
Stator Resistance & $0.00706 \mathrm{p} . \mathrm{u}$ \\
Stator Inductance & $0.171 \mathrm{p} . \mathrm{u}$ \\
Rotor Resistance & $0.005 \mathrm{p} . \mathrm{u}$ (ref. to primary) \\
Rotor Inductance & $0.156 \mathrm{p} . \mathrm{u}$ (ref. to primary) \\
Magnetizing Inductance & $2.9 \mathrm{p} . \mathrm{u}$ \\
Inertia Constant H & $0.2 \mathrm{~s}$ \\
Friction factor & $0.01 \mathrm{p} . \mathrm{u}$ \\
No of Poles & 6 \\
Synchronous Speed & $1200 \mathrm{RPM}$ \\
\hline
\end{tabular}




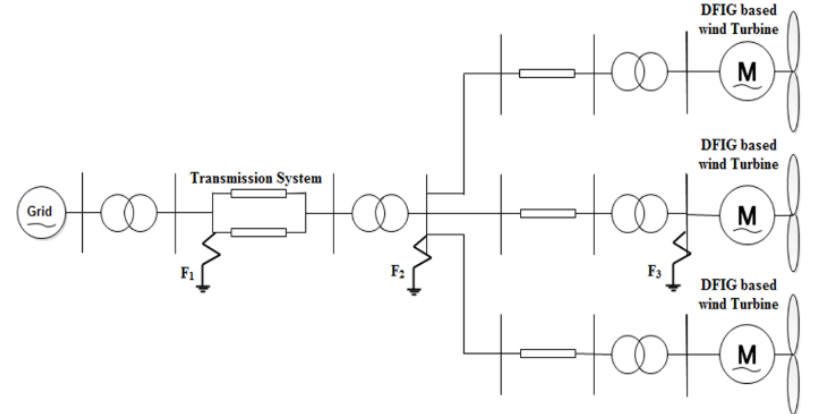

Fig. 5: Configuration of DFIG Based Wind Turbines for Transient Analysis.

\section{Simulation results \& discussions}

The case study on DFIG based wind farm has been carried out in this paper. The Simulink implementation of DFIG by positive sequence phasor model is shown in below Fig. 6 .

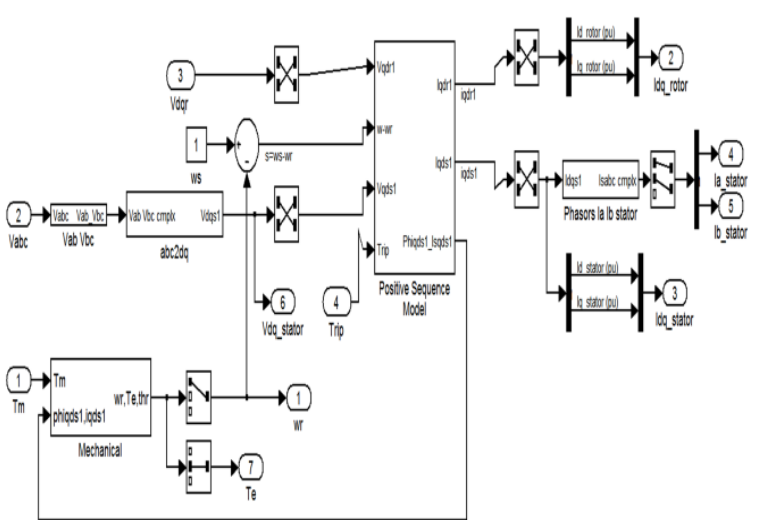

Fig. 6: Simulink design of DFIG.

The system for the transient response of DFIG based wind turbines is shown in Fig. 7. This system contains three wind turbines having variable speeds. The first wind generator has a wind speed ranging between 8 to $15 \mathrm{~m} / \mathrm{s}$, for the remaining two machines the wind speeds are ranging between 9 to $11 \mathrm{~m} / \mathrm{s}$ and 7 to $12 \mathrm{~m} / \mathrm{s}$ respectively. The grid is a fixed AC source; the wind farm is interconnected through a parallel circuit transmission line with two transformers.

For the transient analysis of the proposed configuration, two case studies have been considered. In case 1 , all the faults created on the system are LL faults. In case 2, for the same system two LL faults and LLL fault are created at similar fault locations.

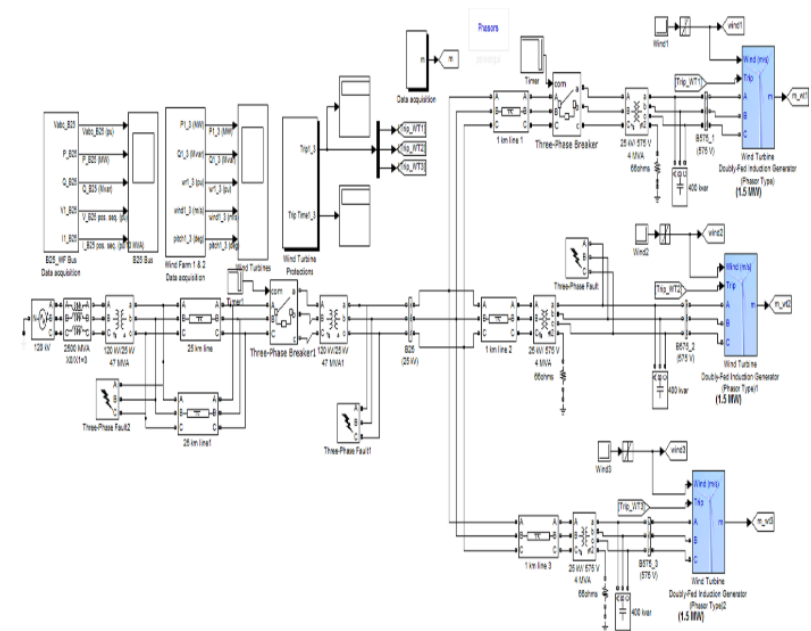

Fig. 7: Simulink Design of Grid Connected Wind Farm with Different Fault Locations.
Case 1:

The faults for the transient analysis are LL fault created for different time durations. The first fault is created at one of the parallel circuited transmission line at grid side for time duration of $0.3 \mathrm{sec}$ from 2.0 to $2.3 \mathrm{sec}$. Second fault is created at PCC where the three wind generators and grid are interconnected for time duration of $0.2 \mathrm{sec}$ from 12.3 to $12.5 \mathrm{sec}$. Third fault is located at second wind generator stator terminals for duration of $0.5 \mathrm{sec}$ from 8.0 to 8.5 sec. The three DFIG wind turbine generators are protected for unbalance, over and under voltages, low and high speeds. Once the trip signal is generated the wind turbine is disconnected after time duration of $5 \mathrm{sec}$.

The simulation results of active and reactive power, rotor speed and pitch angle variation of three wind generators individually for the three faults are shown in Fig. 8. The three generators are delivering 0.2 MW and consume 0.2 Mvar for stable operation.

(A)
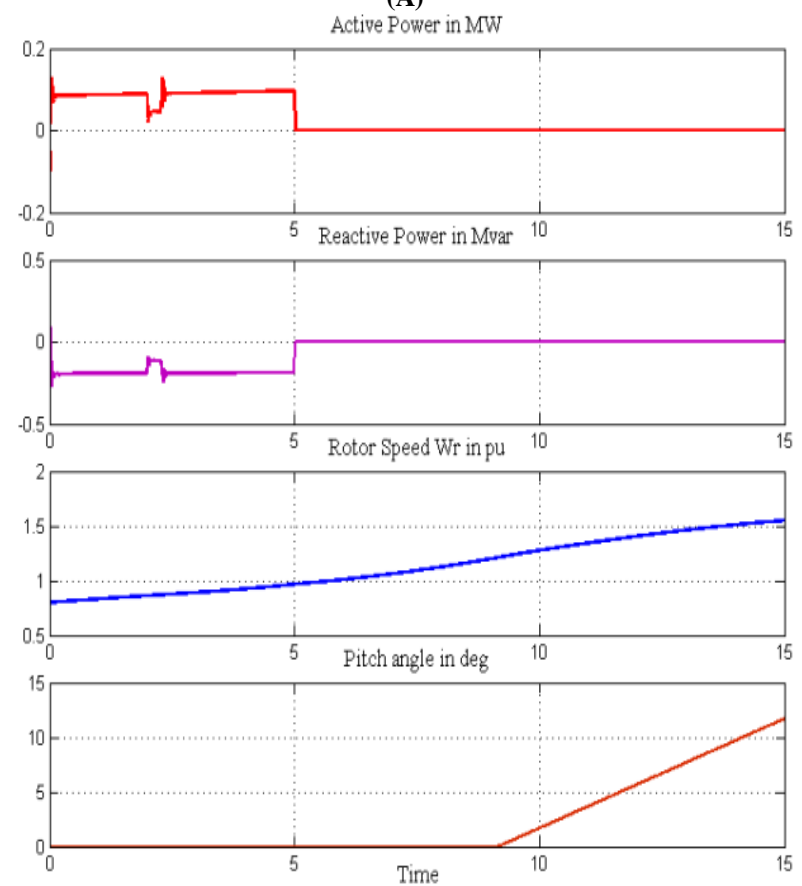

(B)
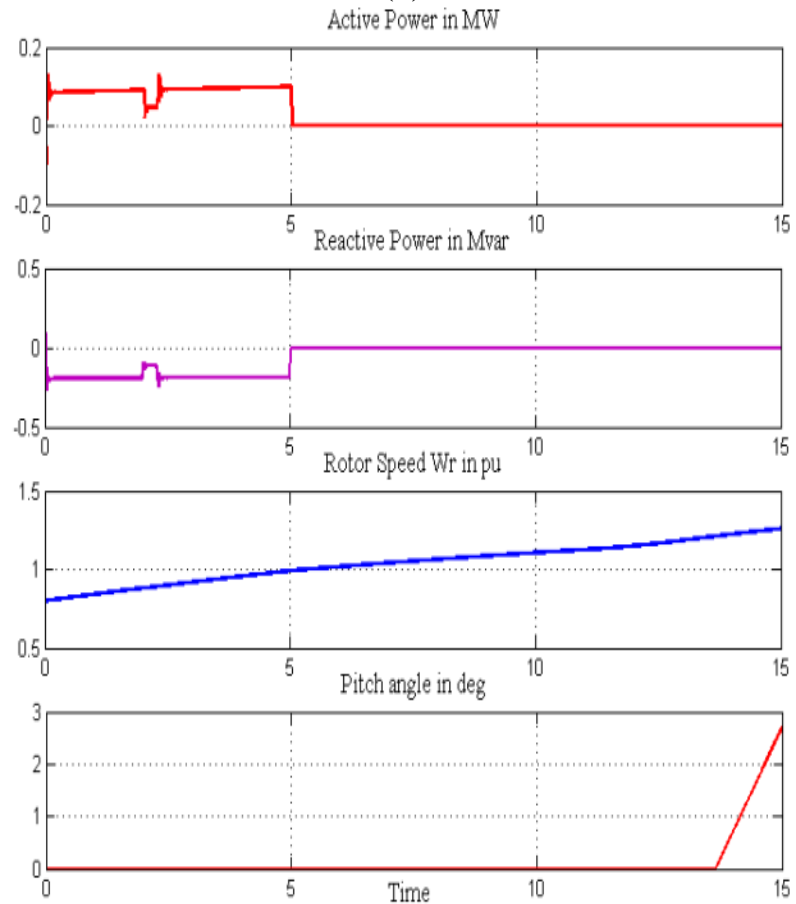
(C)
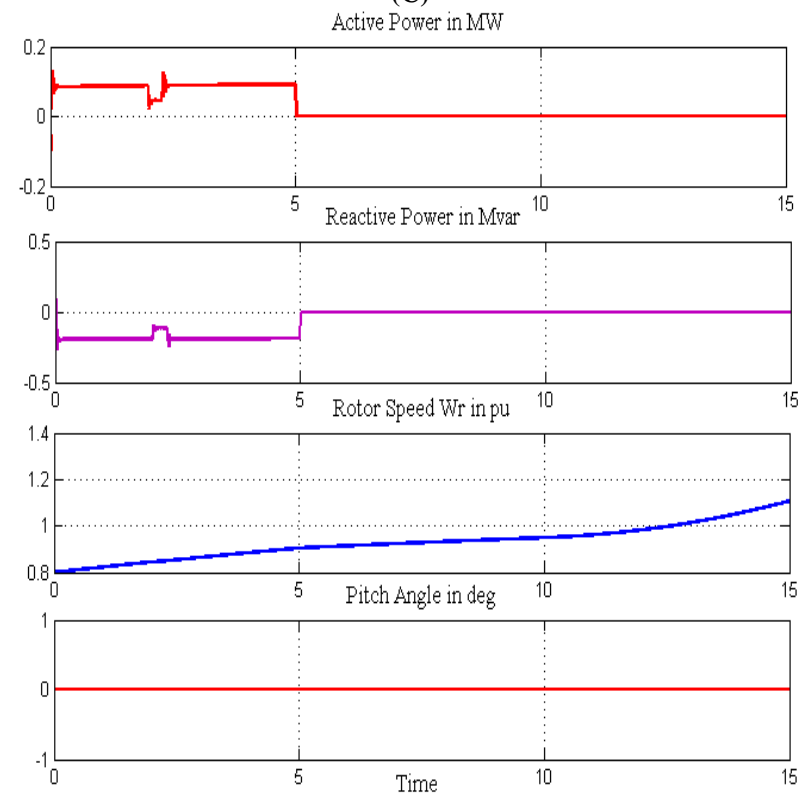

Fig. 8: Active Power, Reactive Power, Rotor Speed, Pitch Angle Variations of (A) Wind Turbine -1 (B) Wind Turbine -2 \& (C) Wind Turbine -3
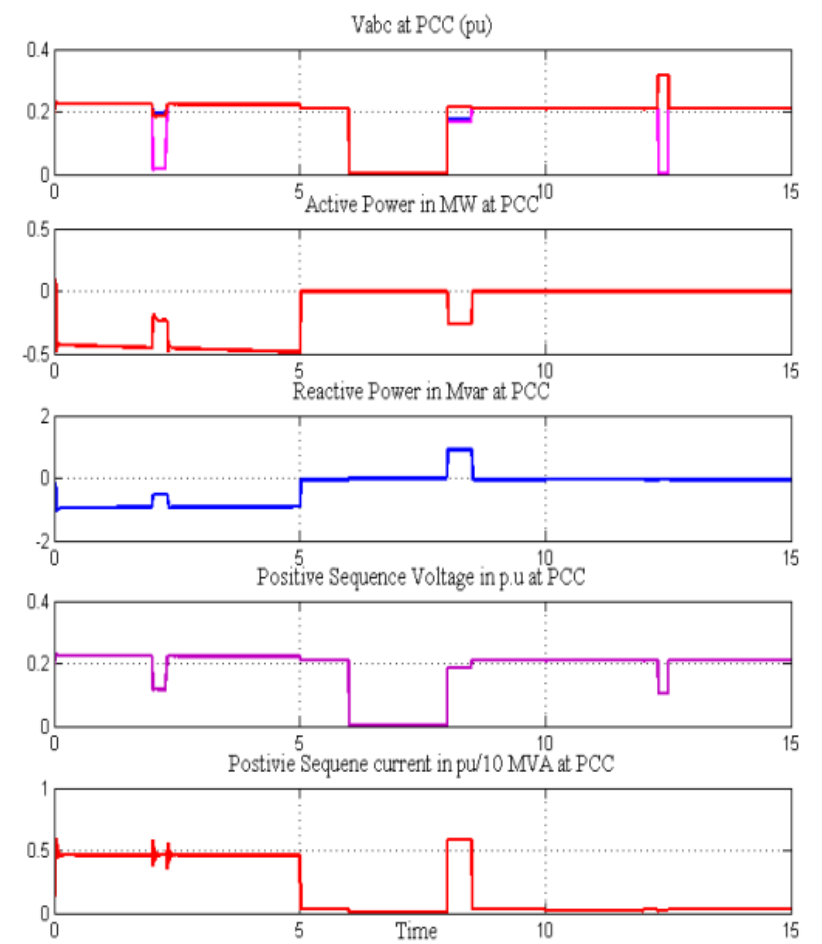

Fig. 9: Voltage, Active \& Reactive Power, Positive Sequence Voltage and Current Variations at PCC during Faults.

At $5 \mathrm{sec}$, the wind turbines are disconnected due to under voltage problem due to low speeds. Due to the fault on the transmission line at $2 \mathrm{sec}$ the active power delivered is decreased about half. The rotor speeds of the alternators are increasing linearly. At $2 \mathrm{sec}$ due to the LL fault on one of the parallel line the line voltage is down to 0.3 pu and the active power delivered by the wind turbines is reduced. The positive sequence voltage decreased to $0.1 \mathrm{pu}$.

From Fig. 9. it can be observed that during the fault at wind turbine side from 8.0 to $8.5 \mathrm{sec}$, the voltage at PCC is dropped near to 0.01 p.u for all the phases and reactive power delivered from the grid is increased after the fault duration to bring back the voltage to 0.2 p.u. During the fault at PCC for $0.2 \mathrm{sec}$ the faulty phase voltages are dropping down to 0.001 p.u and the healthy phase voltage is raised to 0.3 p.u. The positive sequence voltage component of voltage is dropped to 0.1 p.u. The fault at PCC is more dangerous than all the fault locations during fault studies.
Case 2:

In case 2, for the same system two LL faults and LLL fault are created at transmission line, generator side and PCC respectively. Considering all the wind turbines connected to grid before $5 \mathrm{sec}$ omitting the low speed. LL fault on parallel line and wind generator- 2 is occurred at $1.3 \mathrm{sec} \& 3 \mathrm{sec}$ respectively. The LLL fault is occurred at PCC created at 2 sec.
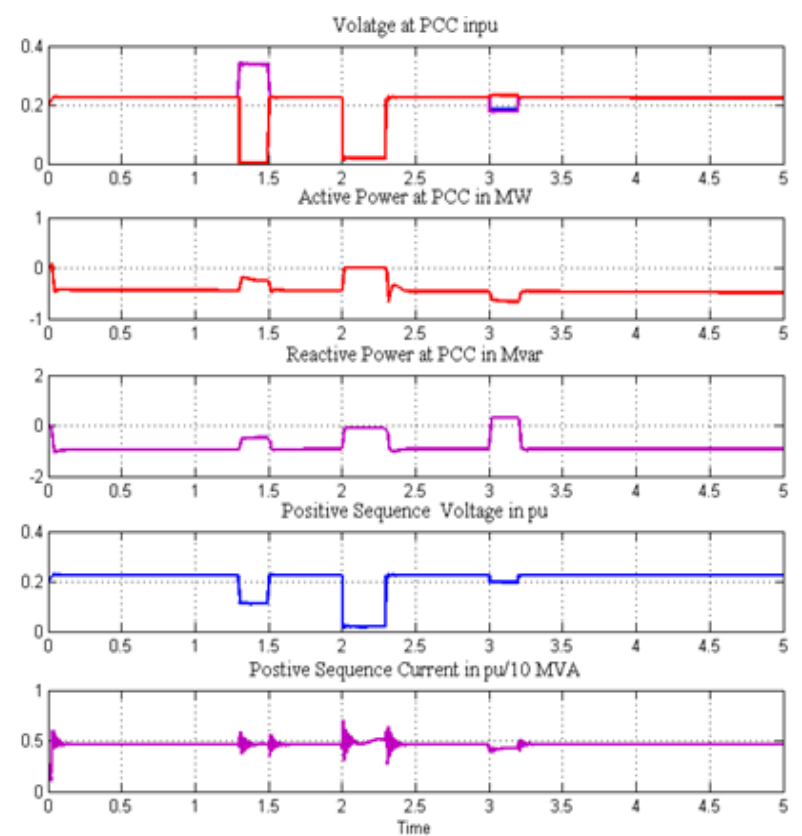

Fig. 10: Voltage, Active \& Reactive Power, Positive Sequence Voltage and Current Variations at PCC during Faults.

From the Fig. 10. It can be seen that, during the fault on line the voltage is dropped to zero value and the fault at PCC causes the voltage dropped to 0.01 p.u.

\section{Conclusion}

The transient behavior of grid interconnection of DFIG based wind turbines are presented in this paper. This paper evaluates the fault on the system at all the possible locations to find the effect on the performance of the wind turbines connected to system. Line to Line and LLL faults are created for test studies. Out of all fault locations the fault near the grid will have more impact on the system operation. The trip signal generation for disconnection of wind farms is fixed to $5 \mathrm{sec}$ depending on the voltage and current operating limits of the DFIG wind generator.

\section{References}

[1] windergy.in/ wind statistics- Windergy-Annual-Statistics-2017.

[2] Amor, Walid Ouled, and Moez Ghariani. "Modelling and Simulation for variable speed wind energy conversion systems based on doubly-fed induction generator." In Electrical Sciences and Technologies in Maghreb (CISTEM), (2014), pp. 1-6.

[3] Chaithanya, S., Reddy, V.N.B. and Kiranmayi, R. "A State of Art Review on Offshore Wind Power Transmission Using Low Frequency AC System". International Journal of Renewable Energy Research (IJRER), Vol. 8, No. 1 (2018), pp.141-149.

[4] Kumar, P. Vinodh, K. S. Meera, and Sasi K. Kottayil. "Transient Fault Response of Grid Connected Wind Electric Generators." International Conference on Power Electronics, Drives and Energy Systems (PEDES'06), 2006.

[5] Chaithanya Seetha, V. Naga Bhaskar Reddy, and R. Kiranmayi. "A narrative review on offshore wind power transmission using low frequency AC system." In IEEE International Conference on Smart Technologies for Smart Nation (SmartTechCon), (2017), pp.52-58.

[6] Erlich, I., Kretschmann, J., Fortmann, J., Mueller-Engelhardt, S. and Wrede, H., Modeling of wind turbines based on doubly-fed 
induction generators for power system stability studies. IEEE Transactions on power systems, 22(3) (2007), pp.909-919. https://doi.org/10.1109/TPWRS.2007.901607.

[7] Seetha Chaithanya, V Naga bhaskar reddy, R Kiranmayi, "A Review Analysis of Offshore Wind Power Transmission using Fractional Frequency AC System", International Journal of Control Theory and Applications, Vol. 10 No. 28, (2017), pp.167-175

[8] Camara, M. S., M. B. Camara, Brayima Dakyo, and H. Gualous. "Modeling and Control of the Offshore wind energy system based on 5MW DFIG connected to grid." In AFRICON, (2013), pp. 1-5.

[9] Subrahmanyam, R., and S. Krishnarjuna Rao. "Techniques of decreasing impedance of an iron cored inductor." In Proceedings of Signal Processing, Communication, Power and Embedded System (SCOPES), (2016), pp. 547-552.

[10] Chowdhury, M.A., Shen, W., Hosseinzadeh, N. and Pota, H.R. Transient stability of power system integrated with doubly fed induction generator wind farms. IET Renewable Power Generation, Vol. 9, No. 2 (2014), pp.184-194. https://doi.org/10.1049/iet-rpg.2014.0035.

[11] S.Krishnarjuna Rao, D.Lenine, P.Sujatha, "Enhancement of Induced EMF throughheat treatment of ferromagnetic core" IEEE International Conference on Power, Control, Signals and Instrumentation Engineering (ICPCSI), (2017) pp. 875-879.

[12] MATLAB documentation center [online] on http:// www.mathworks.co.jp/jp/help. 